\title{
PROPOSTA DE ORGANIZAÇÃO DE ESTOQUES EM UMA EMPRESA ALIMENTÍCIA
}

Amanda C. Teixeira (Universidade Estadual de Maringá) acteixeira2@uem.br José C. O. dos Santos (Universidade Estadual de Maringá) jcosantos@uem.br Camila M. K. Bisotto (Universidade Estadual de Maringá) camilakorchak@ gmail.com

Luiz G. Chaves (Universidade Estadual de Maringá) guga.goio@ hotmail.com

\section{Resumo}

A organização de produtos dentro de uma empresa, sejam as matérias-primas, produtos em proceso ou produtos acabados podem significar ganho de tempo. O local e a forma como itens estão armazenados interferem tanto para quem utiliza os produtos, com facilidade de manuseio, quanto para quem gerencia, identificando sobra ou falta de material. Este estudo apresenta uma parte de um trabalho realizado em uma empresa do ramo alimentício em Goioerê/Paraná. O foco do estudo foi analisar a forma de armazenagem dos estoques da empresa, de matériasprimas e produtos acabados. Visitas à empresa e análise da distribuição dos produtos foram realizadas para conseguir propor, com base em buscas na literatura, uma outra forma de armazenamento, buscando otimizar o espaço e a qualidade desses estoques. Conforme análise os produtos estavam distribuídos de forma não uniforme e com má utilização dos ambientes (camaras frias e freezers). A proposta apresentada conta com a diminuição de dois freezers, e uma distribuição de produtos acabados e matérias-primas.

Palavras-chave: Alimentos, Armazenagem, Arranjo-físico, Pequeno porte.

\section{Introdução}

Atualmente, as organizações buscam crescer competitivamente e conquistar seu lugar no mercado. Um ponto a ser destacado é o de arranjo físico, pois para se ter um processo produtivo organizado, deve-se realizar um planejamento para posicionar equipamentos em lugares estratégicos (AMARAL, et al, 2012).

É de importância em qualquer organização, a maneira de realizar um planejamento para se alocar as máquinas e equipamentos otimizando o fluxo de produção, denominado como arranjo físico. O arranjo físico está diretamente interligado com a produtividade, pois com o planejamento realizado, o processo produtivo pode ser otimizado ou prejudicado, variando de acordo com a alteração física dos equipamentos (PARANHOS, 2007). 
A literatura apresenta quatro tipos de arranjo físicos, arranjo físico posicional, arranjo físico por processo, arranjo físico por produto e arranjo físico celular. O arranjo físico posicional tem como objetivo a transformação de vários processos, permanecendo estacionado, enquanto que os materiais, as pessoas e os equipamentos atuam ao seu redor. $\mathrm{O}$ arranjo físico por processo tem como função a ordenação das máquinas com o processo que será executado. Já o arranjo físico por produto, tem como função agrupar os equipamentos com o produto a ser executado. E por fim, o arranjo físico celular, tem como prioridade o fluxo unitário das peças ao longo do processo produtivo. A literatura também apresenta que, esses arranjos físicos podem combinar entre si, de acordo com as necessidades da empresa (PARANHOS, 2007).

Em qualquer organização, o arranjo físico e o estoque estão interligados, pois o estoque é o acúmulo de materiais armazenados em um sistema, então devido a esse excesso, para alocação de itens e otimização do fluxo de produção, o estoque e o arranjo físico são importantes para uma organização (SILVA, 2019).

De acordo com Slack, Chambers e Jhonston (2002, p. 20), "estoque é a acumulação armazenada de recursos materiais em um sistema de transformação”. Já para Ballou (2006), estoque são o acumulo de itens, distribuídos pela área de produção das empresas.

De acordo com Severo Filho (2006), o estoque é classificado em quatro tipos, de acordo com o tamanho da empresa, a atividade da empresa e a natureza dos produtos classificados, são eles:

- Estoques de matéria-prima e materiais auxiliares: são identificados como os materiais brutos que são destinados a transformação. E também são encontrados neste estoque, componentes ou subprodutos que integrarão no produto final.

- Estoques de Produtos e Processos: São todos os produtos que são utilizados para a montagem ou fabricação do produto final.

- Estoques de produtos acabados: São os materiais ou produtos que em condições a serem vendidas. Muitas vezes são encontrados em depósitos próprios para a expedição.

- Estoque operacional: Constituído de peças sobressalentes ou componentes, lubrificante ou qualquer material utilizado para a manutenção, reparos ou substituições, para que evite possíveis interrupções na produção por quebra ou defeitos de equipamentos.

- Estoques de materiais administrativos: São os materiais utilizados na parte administrativa, destinados ao desenvolvimento das atividades organizacionais.

A Gestão de estoque tem como principais objetivos a antecipação da demanda, o favorecimento 
de ganhos com a economia de escala e racionalização do processo produtivo, a redução de tempos de reposição e também a compensação de transtornos imprevistos em processos produtivos (ACCIOLY; AYRES; SUCUPIRA, 2008).

Logo, a gestão de estoque, envolve diferentes atividades, desde o planejamento e a programação das necessidades de materiais em estoque até no controle das quantidades adquiridas, no qual é mensurado a sua movimentação, armazenagem, localização e utilização, para que possa atender o cliente na qualidade, na quantidade, no preço e nos prazos (SEVERO FILHO, 2006).

É fundamental um bom planejamento e controle de estoque, para que não ocorra prejuízos devido a má gestão de estoque. Principalmente no ramo alimentício, por ser alimentos não perecíveis e para que não ocasione danos a qualidade do produto.

Nos últimos anos, o setor alimentício vem ganhando muito espaço no mercado. No ano de 2018, o crescimento no Brasil desse setor chegou a 2,08\%, alcançando um total de R $\$ 656$ bilhões, gerando um total de treze mil empregos. Esses dados foram divulgados em 13 de fevereiro de 2019 pela Associação Brasileira da Indústria de Alimentos (Abia), no estado de São Paulo (ALBUQUERQUE, 2019).

\section{Objetivos}

O objetivo geral do artigo, é criar um modelo como sugestão, e rearranjo físico dos equipamentos de armazenagem da empresa Trivial Salgados. Para isto, os objetivos específicos são:

- Realizar visitas a empresa;

- Analisar e identificar o fluxo dos processos;

- Analisar a distribuição do estoque;

- Sugerir um modelo de organização para os produtos.

\section{Metodologia}

Para a realização deste trabalho, os métodos utilizados foram as pesquisas descritivas, exploratórias, explicativas, e bibliográficas, que serão apresentadas a seguir. 
O estudo ocorreu em uma empresa de pequeno porte, do ramo alimentício, que produz salgados recheados. Localizada na cidade de Goioerê, no estado do Paraná, a empresa fornece seus produtos para outras empresas da região (supermercados e padarias).

A seguir estão descritas as fases e atividades para os procedimentos deste trabalho:

- Visitar a empresa e coletar de dados;

- Analisar os dados e realizar pesquisas bibliográficas sobre arranjo físico e gestão de estoque;

- Propor um modelo para organização dos estoques.

Primeiramente, entrou-se em contato com a proprietária da empresa, para que se pudesse realizar uma visita em todas as áreas de produção para a realização da coleta de dados do processo produtivo. Após a aprovação da proprietária, os dois acadêmicos visitaram a empresa, e com o auxílio da proprietária foram realizadas vistorias nos freezers e câmaras frias. Em cada parte da empresa visitada, foram anotados os tipos de produtos encontrados, suas respectivas quantidades e onde cada um se localizava. Também foi realizado a solicitação da planta baixa da empresa.

Com os dados em mãos, foi criada uma tabela no software Excel 2010, no qual, foram separados os itens coletados por local de armazenagem, produtos e quantidades. Também se utilizou o software CorelDRAW 2018 para representar a localização dos freezers e câmaras frias dentro da empresa.

Após a análise dos dados coletados, e realizar um levantamento em pesquisas bibliográficas sobre arranjo físico e gestão de estoque em empresas do ramo alimentício, chegou-se a uma sugestão de melhoria.

\section{Resultados e discussões}

De acordo com a metodologia apresentada, a seguir serão apresentados dois subtítulos. O subtítulo 4.1 se trata do modelo atual da empresa, no qual foi a base para o desenvolvimento deste trabalho. Já o subtítulo 4.2 apresenta o modelo criado com base em pesquisas bibliográficas, como sugestão para a empresa, em relação a um novo arranjo físico. 


\subsection{Modelo atual da empresa}

A empresa estudada iniciou seus trabalhos em março de 1998, em um pequeno edifício no Centro Comunitário do Conjunto Cidade Alta de Goioerê (Paraná). Durante dois anos nessa instalação a empresa fabricava apenas pão-de-queijo.

Hoje em dia a empresa se localiza na Avenida Marinho Tavares, é composta por doze funcionários, e produz cerca de vinte e cinco tipos de salgados. Dentre estes produtos também são fabricados bolacha de nata, pastelzinho de goiabada e feijoada para a venda aos finais de semana.

Estima-se a venda de aproximadamente oitenta mil salgados por mês, e no período de férias de verão e inverno essas vendas caem cerca de trinta por cento. Os salgados são distribuídos pela região do estado do Paraná, onde há nove distribuidores fixos e cinco supermercados da região. Dentre todos os tipos de salgados produzidos, o mais vendido é o pão de batata com recheio de frango e catupiry.

De acordo com o gerente da empresa são entregues produtos perecíveis toda semana por fornecedores e quando não-perecíveis são entregues a cada dois meses aproximadamente.

Uma análise prévia foi realizada e constatou-se que não há um sistema de controle dos estoques, é utilizado apenas um sistema para emissão de notas fiscais dos produtos comprados. De acordo com a proprietária já foram realizadas algumas tentativas de implementação de um sistema de banco de dados, porém, sempre houve conflito de dados entre as planilhas e os estoques reais.

Os estoques apresentam uma ampla variedade de produtos, que são dispostos em quatro freezers e duas câmaras frias, que podem ser vistas na Figura 1, que apresenta a planta baixa atual da empresa. O software CorelDraw foi utilizado pelos autores para inserir os locais de armazenamento (camaras frias e freezers). 
Figura 1 - Planta baixa da empresa

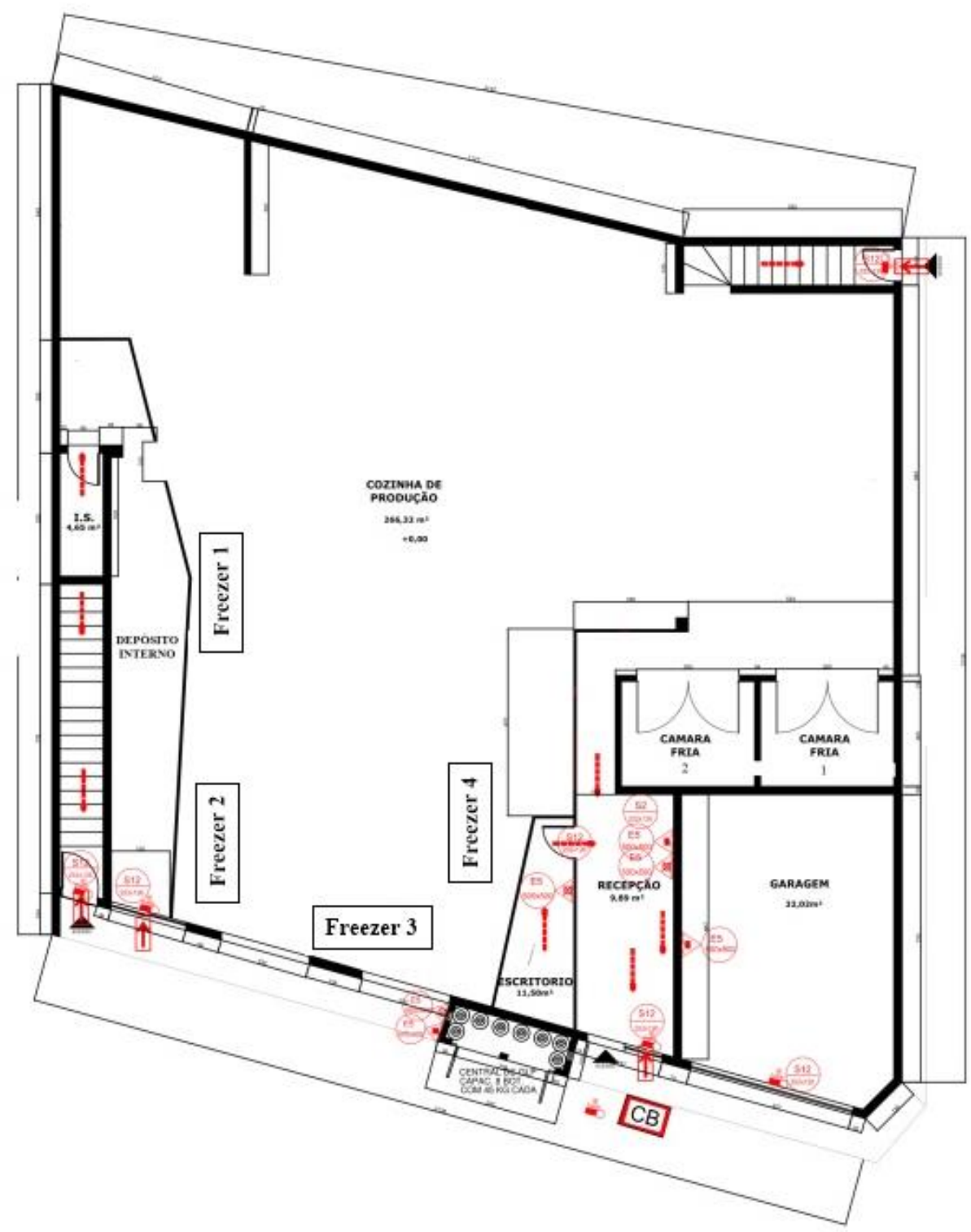

Fonte: Autores (2020)

A Figura 1 mostra como o arranjo físico do ambiente está distribuído, o depósito interno, os freezers, câmaras frias, a cozinha para a produção, bem como a localização da recepção da e escritório da empresa.

A Tabela 1 apresenta os dados coletados por meio das visitas realizadas na empresa, dos itens armazenados e suas respectivas quantidades nas câmaras frias 1 e 2, dos freezers $1,2,3$ e 4 e o depósito. Para analisar os dados, na sua elaboração foi utilizado o software Microsoft Excel 2010. 
Tabela 1 - Produtos armazenados na empresa alimentícia

\begin{tabular}{|c|c|}
\hline Local de armazenagem & Produtos - Quantidade \\
\hline \multirow{4}{*}{ Câmara fria 1} & Frango -12 caixas \\
\hline & Presunto e queijo ralado \\
\hline & Salgados embalados \\
\hline & Pizzas - 10 unidades \\
\hline \multirow{4}{*}{ Câmara fria 2} & Presunto congelado -11 unidades \\
\hline & Salgados embalados \\
\hline & Linguiça calabresa -14 pacotes \\
\hline & Pizzas - 20 unidades \\
\hline Freezer 1 & $\begin{array}{l}\text { Presunto resfriado }-14 \text { unidades } \\
\text { Produtos semi-preparados para ser usado no } \\
\text { dia }\end{array}$ \\
\hline \multirow{6}{*}{ Freezer 2} & Fermento biológico fresco -20 unidades \\
\hline & Mozarela -5 unidades \\
\hline & Gema - 17 caixas \\
\hline & Ricota -5 unidades \\
\hline & Tomates \\
\hline & Leite -3 pacotes \\
\hline Freezer 3 & Frango preparado para ser usado no dia \\
\hline Freezer 4 & Catupiry - 12 pacotes \\
\hline
\end{tabular}

Fonte: Autores (2020)

Ao analisar a Tabela 1, os itens das câmaras frias 1 e 2, apresentam matérias-primas e produtos acabados, não tendo um padrão para o armazenamento, nenhum tipo de identificação nas caixas com os salgados e com acumulado, dificultando a visibilidade dos itens.

Os freezers 1, 3 e 4 são do mesmo tamanho, suas características são: horizontal, duas portas e com capacidade de quinhentos e trinta e quatro litros. Já o freezer 2 apresenta seis portas, é vertical e sua capacidade é de mil e quatrocentos litros.

Nos freezers 1, 2 e 4 há uma desorganização, pois produtos semi-preparados para uso diário estão dividindo o mesmo espaço com produtos ainda lacrados, de acordo com a Tabela 1. Já no freezer 3 são armazenadas as matérias-primas para uso diário, dispostas em bacias de plástico, ocasionado a ocupação excessiva dos espaços. 


\subsection{Modelo proposto}

Conforme apresentado na metodologia, foi realizado um levantamento de pesquisas bibliográficas sobre arranjo físico e gestão de estoque em empresas do ramo alimentício. Com isso, foi possível se chegar a uma sugestão de melhoria, que será apresentada no decorrer do subtópico.

Ao realizar a análise dos dados no subtópico 4.1, e com base na literatura, observou-se que seria necessário realizar a gestão de estoque em todos os equipamentos de armazenagem, pois os estoques estavam desorganizados, por apresentarem itens acumulados, com matérias-primas e produtos acabados sem nenhum tipo de divisão.

A implementação de um sistema de banco de dados para o controle de estoque seria necessário, pois, conforme descrito pela proprietária, já havia ocorrido algumas tentativas, porém sem sucesso. Então, esse sistema deveria ser simples e prático, para que se pudesse ser manipulado sem dificuldade.

De acordo com a Norma Reguladora $\mathrm{N}^{\circ} 12$

"12.7 Os materiais em utilização no processo produtivo devem ser alocados em áreas específicas de armazenamento, devidamente demarcadas com faixas na cor indicada pelas normas técnicas oficiais ou sinalizadas quando se tratar de áreas externas"

Segundo Moura (2008), a melhor forma de armazenar materiais ou produtos, é a que aproveite todo o espaço físico, desde que haja a otimização.

A Figura 2 apresenta a sugestão de melhoria do arranjo físico para a empresa, baseando-se em pesquisas bibliográficas sobre o tema em empresas do ramo alimentício. 
Figura 2 - Sugestão de arranjo físico

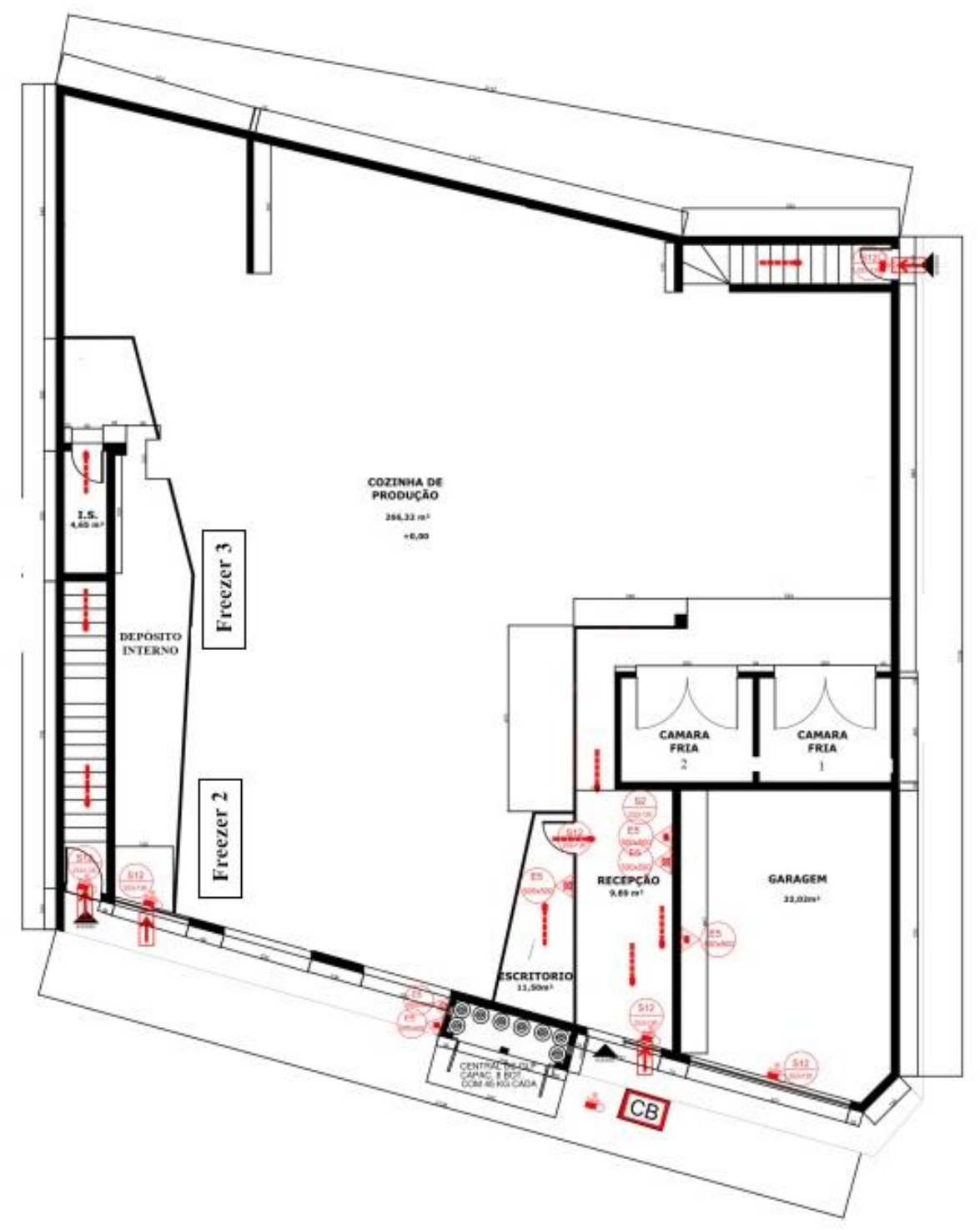

Fonte: Autores (2020)

De acordo com a Figura 2, o novo arranjo físico dos freezers seria da seguinte forma: o freezer 2 permaneceria na mesma posição que está atualmente, e o freezer 3 seria realocado para a posição atual do freezer 1. Dessa forma, durante o processo produtivo, que houvesse a necessidade de coletar determinado produto, os funcionários buscariam o freezer específico.

A Tabela 2 demonstra a organização dos produtos com base nas pesquisas bibliográficas sobre gestão de estoque em empresas do ramo alimentício. 
Tabela 2 - Organização dos produtos

\begin{tabular}{|c|c|}
\hline Local de armazenagem & Produtos - Quantidades \\
\hline \multirow{4}{*}{ Câmara fria 1} & Frango - 12 caixas \\
\hline & Presunto e queijo ralado \\
\hline & Presunto congelado - 11 unidades \\
\hline & Linguiça calabresa - 14 pacotes \\
\hline \multirow{2}{*}{ Câmara fria 2} & Salgados embalados \\
\hline & Pizzas - 30 unidades \\
\hline \multirow{8}{*}{ Freezer 2} & Presunto resfriado - 14 unidades \\
\hline & Fermento biológico fresco - 20 unidades \\
\hline & Mozarela - 5 unidades \\
\hline & Gema - 17 caixas \\
\hline & Ricota - 5 unidades \\
\hline & Tomates \\
\hline & Leite - 3 pacotes \\
\hline & Catupiry - 12 pacotes \\
\hline \multirow{2}{*}{ Freezer 3} & Frango preparado para ser usado no dia \\
\hline & Produtos semi-preparados para ser usado no dia \\
\hline
\end{tabular}

Fonte: Autores (2020)

Como não há um sistema na empresa para armazenamento de dados dos itens comprados e presentes na empresa, sugere-se a criação de um banco de dados para a estocagem, por meio do software Microsoft Excel. A proprietária ou o gerente ficaria responsável pela manipulação da planilha, e o sistema seria simples, para que não houvesse dificuldades. Haveria colunas para os tipos de itens, preços, fornecedores, quantidades, data de validade e em qual equipamento o produto se localizava. Seriam classificados pela validade, permanecendo no topo da lista os produtos com menor prazo, para facilitar que os esses comprados a mais tempo fossem usados antes e não viessem a estragar. Sendo assim, os itens ficariam organizados no sistema, podendo ser conferidos sempre que necessário, não havendo a necessidade de ir até os equipamentos e fazer a vistoria (PESSOA; LOOS, 2016).

De acordo com a Tabela 2, analisou-se que na câmara fria 1 estava havendo muita variedade de matéria-prima e produtos acabados, ocasionando a ocupação indevida do espaço. Então sugerese a alocação apenas de matérias-primas, e a implementação de novas prateleiras de aço inox nas paredes internas, de forma que os itens pesados seriam alocados na parte inferior e os leves na parte superior, deixando o centro do equipamento livre, facilitando a organização, visualização dos produtos e o acesso dos funcionários. 
Na câmara fria 2, as prateleiras existentes seriam retiradas para a utilização de todo o espaço interno, sendo alocado apenas os produtos acabados (salgados), de forma que eles fossem empilhados e armazenados em caixas plásticas vazadas, e encostados nas laterais da câmara fria, deixando o centro dela livre para se ter acesso e visualização dos produtos. Em cada caixa haveria uma etiqueta com data de validade e nome do produto armazenado.

Existem quatro freezers na empresa, e conforme a reorganização dos itens, os freezers 1 e 4 seriam desligados, e os itens presentes neles que estivessem lacrados seriam transferidos para o freezer 2, por apresentar maior capacidade de armazenamento. O freezer 3 permaneceria e os produtos dos outros freezers para uso diário seriam transferidos para ele. Dessa maneira, ficou como proposta organizar e dividir os produtos em duas classes, a primeira é por matéria-prima (freezer 2) e a segunda por produtos semi-prepados para uso diário (freezer 3). Sendo assim, haveria a economia de energia de dois freezers, que estavam sub-utilizados e liberando espaço dentro da empresa, e também os funcionários não perderiam tempo se deslocando em freezers diferentes para coletar produtos para o processo produtivo.

\section{Conclusão}

Diante do estudo apresentado, foi avaliado o arranjo físico e os estoques da empresa de salgados localizado em Goioerê/PR, com a finalidade de propor melhorias que contribuíssem para um melhor funcionamento da mesma. Por meio de estudos e pesquisas sobre os temas abordados, e das vantagens e desvantagens que o modelo proposto ocasionaria.

O objetivo foi analisar o armazenamento dos produtos na empresa atualmente, buscando as falhas e sugerir uma nova forma do arranjo físico e gestão de estoque. Para isso, foi necessário realizar visitas à empresa, analisar os dados coletados e estudar uma proposta para o projeto.

Conforme analisado, as características da empresa indicaram como ideal, a realocação dos freezers, desenvolvimento de um banco de dados para armazenagem dos itens da empresa, e a gestão de estoque, que ficou subdividida em organizar e separar os produtos por matéria-prima e acabados.

Portanto, a empresa por ser de porte pequeno, não apresentou grandes dificuldades para o desenvolvimento do trabalho, as sugestões propostas foram simples e não necessitou de um planejamento muito detalhado. Dessa forma, fica a critério dos proprietários implementarem ou não a proposta sugerida. 


\section{REFERÊNCIAS}

ACCIOLY, F.; AYRES, A.P.S.; SUCUPIRA, C. Gestão de Estoques. Rio de Janeiro: Editora FGV, 2008. Pg. 11. ALBUQUERQUE, F. Faturamento do setor de alimentos aumentou 2,08\% no ano de 2018. Disponível em: <http://agenciabrasil.ebc.com.br/economia/noticia/2019-02/faturamento-do-setor-de-alimentos-aumentou-208no-ano-passado>. Acesso em 6 de Fev. 2020.

AMARAL, L.; et al. O papel do arranjo físico e da gestão de informações como fermenta para melhoria da competitividade e desempenho dos processos de uma lavanderia industrial. Disponível em: < http://www.revistaseletronicas.fmu.br/index.php/rms/article/view/193>. Acesso em 6 de Fev. 2020.

NR, Norma Regulamentadora Ministério do Trabalho e Emprego. NR-12 - Segurança no Trabalho em Máquinas e Equipamentos, 2009.

PARANHOS, M.F. Gestão da Produção Industrial. Curitiba: Ibpex, 2007. Pg. 217.

PESSOA, S.F.; LOOS, M.J. O uso de planilhas para controle de estoques em uma empresa do ramo de alimentos. Disponível em: <https://www.revistaespacios.com/a17v38n18/a17v38n18p30.pdf>. Acesso em 7 de Fev. 2020.

SEVERO FILHO, J. Administração de logística integrada: materiais, PCP e marketing. $2^{\text {a }}$ ed. Rio de Janeiro: E-papers, 2006. Pg. 62 e 63.

SILVA, B.W. Gestão de Estoques: Planejamento, Execução e Controle. $2^{a}$ ed. João Monlevade: BWS Consultoria, 2019. Pg. 58.

SLACK, N; CHAMBERS, S; JONHSTON, R. Arranjo Físico e Fluxo, Administração da Produção. $2^{\mathrm{a}}$ edição, 2002. 